\title{
Value Creation and the Pursuit of Multi Factor Productivity Improvement
}

\author{
Roy Woodhead ${ }^{1 *}$, Mohammed Ali Berawi ${ }^{2}$ \\ ${ }^{1}$ Business Operation Systems, Sheffield Business School, Sheffield Hallam University, 38 - 40 Howard Street, \\ Sheffield S1 1 WB, United Kingdom \\ ${ }^{2}$ Department of Civil Engineering, Faculty of Engineering, Universitas Indonesia, Kampus UI Depok, Depok \\ 16424, Indonesia
}

\begin{abstract}
This paper links Value Management to macro-economics to explore transformational innovation. It borrows from economics and the relationship between technological progress and rising living standards for citizens. Central to this is seeing 'technology' in a wider sense than devices. What makes this paper different is it attempts to link Government spending on capital projects directly to economic growth in an economy. Whilst macroeconomists use historic data, this paper applies those theories to the conceptual stages of capital-projects to become part of a Government's investment appraisal process. As such, this paper outlines a 'how to' approach that will help Governments prefer Foreign Investments that lead to long-term economic growth. The hope is that this paper will stimulate other researchers to replicate the methodology and in so doing open a new direction for innovation methodologies such as Value Engineering and Value Management that link capital projects to growth in GDP.
\end{abstract}

Keywords: Capital projects; Economic growth; Government; Innovation; Productivity; Value management

\section{Introduction}

The field of Value Management (Woodhead and Male, 2000; Woodhead, 2001; Kaufman and Woodhead, 2006; Male et al., 2007; Berawi et al., 2014; Teschl, 2018; Visser, 2019) has confined itself to micro-economics. In this paper we extend it to macroeconomics to explain how economists understand the role of technological progress as a key determinant of economic growth at the national level (Wiratmadja et al., 2016). This stands on ideas linked to productivity and production functions. However, economists use historic data and given low and even negative productivity statistics in many countries, we argue there needs to be a proactive way to influence economic growth. We start by reviewing established ideas from economists before exploring how we could adopt a more proactive approach that would help Governments not only deliver capital projects that their citizens need, but also in ways that stimulate productivity and a consequential rise in prosperity. We do so by sharing a method that could be used in the conceptual stages of a capital project, alongside established investment appraisal techniques. The hope of this paper is to start new lines of research in the field of Value Management. 


\section{Methods}

This paper draws upon Nobel Prize winning economics and through logical deduction adapts approaches based on historic data to become applicable to projects not yet implemented. In this section we explore existing literature and outline the case for a new approach to help Governments to use capital projects to stimulate longer term economic growth beyond the project itself.

\subsection{Innovation and Value}

History is replete with examples of 'substantive' technological innovation (Schumpeter, 1942; Christensen, 2016). It is also common to see established organisations fail to recognise the need to adapt until it is too late. Laggards seem to seek profit maximisation in the short run without adequately funding R\&D for their long-term adaptation and survival; Leonard-Barton (1995) explains early successes become core rigidities that trap them in the past. The gap between how they created value in the past and how they need to create value in the future widens. The cause of this gap is at the heart of this paper.

In this paper we are speaking of 'substantive' technological innovation. They are substantive innovations because they cause society to adapt. Karl Marx in 1847 (Marx and Engels, 1976) discussed how societies evolved because of forms of technological innovation reshaping them and in "The Poverty of Philosophy" gave the now famous dictum:

The hand-mill gives you society with the feudal lord; the steam-mill, society with the industrial capitalist.

A Government that 'knows' how to stimulate economic growth within planned budgets is at an advantage. Rational choices at the macro level are modelled by economists with respect to a Production Possibility Frontier (PPF). Their idea is that a country creates wealth by converting scarce resources, as inputs, into outputs within a relationship between producers and consumers where actors seek to maximise their own value (e.g. Adam Smith's Invisible Hand; Smith, 1776). By improving productivity the PPF is expanded and the standard of living of citizens rises. The way such improvements are enabled is through technological progress.

\subsection{Innovation and Functionality}

The key to innovation is the improved performance of functionality (Kroes, 1998; Seni, 2005; Berawi and Woodhead, 2005; Berawi, 2006; Berawi and Woodhead, 2008; Berawi, 2018). A number of innovation methodologies either explicitly (e.g. Value Engineering) or implicitly (e.g. TRIZ) attempt to clarify ideas of functionality to explain how products or systems yield benefits.

In such methodologies, the idea of functionality is in the context of some act of purposeful design. In an approach like algebra in which a problem is represented in terms of symbols, an existing solution is deconstructed to reveal a theory of its inherent functionality in a way that separates physical implementations from their intended usefulness. Once a theory of functionality has been made explicit and visible, a team then considers alternative ways of performing those functions. As with most creative processes there is an element of serendipity at play and inventiveness is done within a value-seeking bias. If the methodology has been successful then as a minimum the same functions can be performed in ways an investor sees as more beneficial.

It is also possible to consider multiple products or projects and once their individual functionality has been theorised, ways are found to combine the two projects in to one (Berawi et al., 2014). Again, the idea is to ensure the required functionality is performed within a better overall solution. 
A challenge seen in many methodologies is the narrowness in which 'value' is itself measured before and after an intervention. Typically, value is seen in monetary terms. However, such a result may not actually create value for the economy as a whole. This is because the result may not expand the PPF. In fact, we see some economies around the world experiencing negative productivity which implies their PPFs are shrinking yet their Governments still fund capital projects based on financial investment criteria alone (e.g. ROI).

Economists pursuing the idea of technological progress found a variable linked to economic growth in GDP. This variable is commonly called either Multi-Factor Productivity (MFP) or Total Factor Productivity (TFP), the two terms used interchangeably.

\subsection{The Idea of Multi Factor Productivity and Total Factor Productivity}

Productivity is a ratio of outputs to inputs and was discussed by Smith (1776) where he examined the output of hat pin makers in different configurations of a production process. Smith showed how for the same labour and capital costs, the 'division of labour' increased outputs. It is from this line of thinking that the modern ideas of MFP and TFP have evolved.

OECD (2001) defines MFP as:

"Multi-factor productivity (MFP) relates a change in output to several types of inputs. MFP is often measured residually, as that change in output that cannot be accounted for by the change in combined inputs."

The core idea is that output is a function of both labour and capital that replaces or augments labour.

The literature shows a series of developing production functions that became foundational ideas others built upon to develop keener insights in to what causes GDP to grow. After all the factors that cause growth have been identified, there is typically an amount which cannot be explained. This unexplained factor is what economists call technological progress (also referred to in the literature as technological change or technical change) and is MFP. This concept is at the heart of economic growth accounting at the national level and started in 1928 with what became known as the Cobb-Douglas (1928) production Function:

$$
\mathrm{Y}=\mathrm{F}\left(\mathrm{L}^{\beta}, \mathrm{K}^{\alpha}\right)
$$

Equation 1 says output is a function of some proportion of labour (L) and some proportion of capital (K). This seemed a reasonable model. However, it was just after the Second World War when data became available to academics that Abramovitz (1956) examined output data from 1870 to 1950 in America and considered that alongside input data of labour and capital for the same period (Rosenberg, 2004). His assumption was that output and inputs should be equal, as implied in the Cobb-Douglas model which had been accepted by many. However, to his surprise inputs could only account for around 15\% of the outputs which meant there was an unexplained residual of around $85 \%$. This was a big error no one had noticed.

Rosenberg explains that a number of other scholars undertook similar studies and they too arrived at an unexplained residual of around $85 \%$. One of them was Solow $(1956,1957)$ who attributed the unexplained residual to technological progress. However it later proved difficult to estimate technological progress in ways that consistently explained outcomes in different countries. For example, large capital investments in Africa had failed to produce the economic growth expected. Something else was at play. 
It is important to remember these ideas precede the rise of computers. For economists, the word 'technology' is more closely associated with the study of techniques and so 'technological progress' embraces a much wider view than one focused singularly on a device (Woodhead, 2012). The main agreement amongst economists was that technological progress played a vital role in stimulating long term economic growth, whatever 'technological progress' was. The search was on for a better grasp of what counted as ' technological progress'.

Solow saw labour as growing exogenously through population growth. He did not distinguish different qualities of labour or that some forms of labour could be more valuable to output than others. He also saw capital accumulation as a result of savings behaviour. This implies savings are reinvested as capital. However, Solow argued that 'capital deepening' (increasing capital per worker) could not increase output indefinitely due to diminishing returns and depreciation. He also viewed technology as exogenous even though he explained its role was very important.

Another academic, Swan (1956) developed similar ideas to Solow at the same time and together they created what became known as the Solow-Swan model. Whereas CobbDouglas saw output as a function of labour and capital only (see Equation 1), the SolowSwan model made allowance for Technical Progress (i.e. technological value). Solow-Swan describes Technical Progress as 'capital augmenting' because it increases output in the same way an increase in capital stock does (see Equation 2):

$$
\mathrm{Y}=\mathrm{A}(\mathrm{t}) \mathrm{F}\left(\mathrm{L}^{\beta}, \mathrm{K}^{\alpha}\right)
$$

The ' $\mathrm{A}$ ' in Equation 2 is the term used to measure technical progress (e.g. capital augmentation through say a new training initiative that improves employee productivity).

The Solow-Swan model predicts that in the long run economies converge to their steady state. A challenge they faced was that in steady state they had to explain why their model suggested output and capital grow at the same growth rate (i.e. capital widening) as the labour force did, but evidence from different countries showed output grew faster than these two factors of labour and capital, could explain. For them, technological progress was exogenous.

In the Solow-Swan model, if we accept 'constant returns to scale' then the exponents $\alpha$ and $\beta$ become $\alpha$ and $\beta=1-\alpha$. The Solow-Swan model under this assumption of constant returns to scale becomes (see Equation 3):

$$
\mathrm{Y}=\mathrm{A}(\mathrm{t}) F\left(\mathrm{~L}^{1-\alpha}, \mathrm{K}^{\alpha}\right)
$$

This implies changes in output are a consequence of changes in the mix of labour and capital; one being swapped for the other. It measures technological progress in terms of rising output with respect to constant capital and labour input which leaves a residual. In the remainder of this paper we will assume constant return to scale such that $\beta=1-\alpha$ unless stated otherwise.

Arrow (1962) tried to bring the idea of knowledge in to his model and make it endogenous through "Learning by doing". He saw the gap between inputs (i.e. capital and labour) with respect to output growth as the result of what we'd call today, "working smarter". His argument was that a labour force becomes more productive as a result of learning how to work machines better and learning other ways to achieve greater efficiency in a given mix of capital and labour. Whilst a new tack, there were criticisms of his model as the key variable of technological progress remained exogenous. We would have to wait for Romer (1990a) to show us a way forward. 
Solow continued a line of thinking from Cobb-Douglas that divided the world in to capital and labour and saw this eventually stifles economic growth due to the law of diminishing returns and depreciation. Romer, influenced by Arrow, saw the world differently and divided it in to ideas and objects with the assumption ideas are nonrivalrous, meaning others can replicate an idea to improve their situation which offers the prospect of sustainable growth, so long as there is a flow of new ideas (Nonneman and Vanhoudt, 1995). Whilst capital, labour and objects are finite, ideas are infinite. The implication is an economy can grow beyond Solow's steady state if there is a continual supply of ideas and designs that create value.

Romer (1990a, 1990b) brought the root of technical progress in to his model and made it endogenous. Together, Mankiw, Romer and Weill (1992) they adapted Arrow's view of knowledge and acknowledged human capital $(\mathrm{H})$, a highly skilled form of labour, to distinguish it from unskilled labour. Building on academics before them they offered a new production function that had a constant return to scale in objects but when combined with ideas shows increasing returns to scale. Mankiw, Romer and Weill model:

$$
\mathrm{Y}=\mathrm{K}^{\alpha} \mathrm{H}^{\beta}(\mathrm{AL})^{1-\alpha-\beta}
$$

where $\alpha>0, \beta>0$, and $\alpha+\beta<1$, Y is output, $\mathrm{K}$ is physical capital, $\mathrm{H}$ is human capital (i.e. highly skilled labour), A is technology that augments labour, $\mathrm{L}$ is unskilled labour.

This helped overcome problems the Solow-Swan model encountered. It also called in to question whether large investments in to infrastructure alone are an effective way to lift poor nations out of poverty as what seems to be a better source of wealth creation is an advanced education system that opens the way to advanced technology and a flow of ideas that create value.

Let us assume an economy is in steady state. This gives:

$$
\mathrm{Y}(t)=\mathrm{K}(t)^{\alpha} \mathrm{H}(t)^{\beta}(\mathrm{A}(t) \mathrm{L}(t))^{1-\alpha-\beta}
$$

To understand growth dynamics Canarella and Pollard (2003) and use sk and sh to measure the amount of non-consumed output invested in physical and human capital accumulations. The dot over a variable signifies a derivative with respect to time $(\mathrm{t})$.

$$
\dot{K}(\mathrm{t})=\mathrm{S}_{\mathrm{k}} \mathrm{Y}(\mathrm{t})-\delta \mathrm{K}(\mathrm{t})
$$

Equation 6 shows capital accumulation resulting from a proportion of output saved for investment in physical capital $(\mathrm{sk} Y)$ minus the rate at which existing capital depreciates $(\delta \mathrm{K})$.

$$
\dot{L}(\mathrm{t})=\mathrm{nL}(\mathrm{t})
$$

Equation 7 sees labour accumulation resulting from the growth rate of labour (n) multiplied by the stock of labour (L).

$$
\mathrm{A}(\mathrm{t})=\mathrm{gA}(\mathrm{t})
$$

Equation 8 explains technology accumulation $(\hat{A})$ is found by multiplying the growth rate of technology, which is also called 'technological progress' (g), by the stock of existing technology (A).

$$
\dot{\mathrm{H}}(\mathrm{t})=\mathrm{sh}_{\mathrm{h}} \mathrm{Y}(\mathrm{t})-\delta \mathrm{H}(\mathrm{t})
$$

Equation 9 is a similar idea used for physical capital but here focuses on highly skilled human capital. It shows that the accumulation of human capital results from a proportion of output saved for investment in human capital $(\mathrm{sh} Y)$ minus the depreciation rate of human capital $(\delta \mathrm{H})$ (Groot, 1998; Arrazola and de Hevia, 2004) through say retirement or other 
factors which removes highly skilled workers from the job market. This is a core idea in Romer's model (Romer, 1990a) in that it is the accumulation of human capital that drives economic growth and the supply of new ideas and new designs.

Economists do not stand still and other scholars have evolved these models to explain various aspects (e.g. Baumol, 1986; DeLong, 1988) and in recent times we have also seen the idea of intangibles gain more attention from economic scholars (e.g. Teece, 2015; Haskel and Westlake, 2018).

Whilst the literature on economic growth usually operates at a country level, we want to adapt it to a capital project level so that we can assess potential solutions with respect to their contribution to GDP growth.

In this section of the paper we have shown how the ideas of MFP have evolved and why such concepts are vital as they drive the economic prosperity of nations. However, there is a productivity problem in many economies around the world we cannot ignore.

\subsection{The Productivity Puzzle}

Many nations experience flat or even negative productivity. This phenomenon is often called the "Productivity Puzzle" (e.g. ONS, 2015; Harris and Moffat, 2017; Goodridge, Haskel and Wallis, 2018). The puzzle is that since the economic downturn in 2008 we have seen GDP rise but unusually, productivity has not shown a comparable increase. Something else is going on that is not yet understood. Various reasons have been offered (Goodridge et al., 2018), and the ONS (2015) state:

"Many economists have tried to explain the productivity puzzle but a full explanation remains elusive. Among the many reasons suggested are low levels of investment, the impact of the financial crisis on bank's willingness to lend to new businesses, higher numbers of people working beyond normal retirement age as a result of population and pensions changes, and firms' ability to retain staff because of low pay growth. While these and other factors may be relevant, they do not provide a complete explanation for the weakness in productivity."

We argue that the reason the Productivity Puzzle is unresolved is because Economists try to explain it with historic data. The causes thus become obscured in aggregated measurements. As a thought experiment, imagine a nation's economy, suffering from negative productivity comprises of three large capital projects only. It is possible that two of those projects make a positive contribution to GDP growth which is cancelled out by the other project which has a larger negative contribution. To understand what is going on requires closer examination of the origins of data in projects and business operations. If we 'know' a capital project will make a large negative contribution that nullifies other positive contributions to GDP growth, then there is no longer a puzzle.

\section{Results and Discussion}

\subsection{Economists Calculate MFP with Hindsight}

The way economists calculate MFP is to run a multiple regression over historic data. This leads to a residual, the difference between what the predicted output $(\hat{Y})$ is versus the actual output $(\mathrm{Y})$. They then try to explain away the residuals through analysis of inputs. The bit that cannot be explained away is MFP, also known as the Solow Residual (Barro, 1999).

Our logical deduction flows from the realisation that economists look at what happened in the past rather than forward to influence better results. Therefore, if we can increase the probability of a positive MFP, then it seems reasonable to expect better MFP results. Given the importance of MFP to a nation's economic prosperity, one would expect Governments 
to be interested in such a prospect. To achieve this requires calculation of MFP at the capital project level and using such a calculation as part of Governmental investment appraisal criteria, could avoid projects that undermine the economy's GDP growth. It is also possible that in the act of monitoring planned versus actual, a new cause is realised.

\subsection{How to Calculate MFP a Priori}

Given how important MFP is to a country's economic growth, the question then arises, how do we calculate MFP in capital projects during the conceptual stages where there is instability in predicted revenues and costs? With such an ambition in mind we found a simple explanation of how to calculate MFP on the ONS site (Franklin, 2018). This enables a Government to derive greater value from a capital project by considering the development of lasting know-how, as explained by Nobel Prize winning economist, Romer (1990a). For brevity we describe the key steps below.

Franklin adapts the Solow-Swan model (see Equation 3) by distinguishing labour types in what is called "Quality Adjusted Labour Input" (QALI). This approach assumes the higher earnings potential of more skilled workers reflects "Human Capital". In our equation we show this as $\mathrm{H}_{\mathrm{L}}$

$$
\mathrm{Y}=\mathrm{A} F\left(\mathrm{H}_{\mathrm{L}}{ }^{1-\alpha}, \mathrm{K}^{\alpha}\right)
$$

Where $\mathrm{Y}$ is output which we see as the total paid investment cost of a new project, $\mathrm{A}$ is total factor productivity, the unexplainable element which drives economic growth, HL is the quality adjusted labour input, $\mathrm{K}$ is capital services which could be the cost of a subcontractor that is treated as if it was a capital purchase. This assumption may be necessary for Governments procuring services from the private sector that make input factors hard to measure.

Based on Franklin (2018) explanation we show the following steps. Franklin explains that economists use natural logs rather than arithmetic percentages to accommodate continuous compounding growth and preserve an approximate result no matter in which order numbers were inputted. Following the ONS example we will use natural logs to determine percentage changes. The method we use is:

1. Define both a base case and a new approach.

2. Divide the estimated cost of completion by the number of calendar days in the project to find an estimated output per day.

\section{Calculating Labour Inputs}

1. Calculate the labour inputs per job category and the number in each job category to find the labour costs per day. Also sum to find the total labour cost per day.

2. Divide step 2 by step 3 to find partial labour productivity.

3. Repeat steps 2 to 4 for the new approach.

4. Calculate the percentage change in output between the two methods from step 2

5. Calculate the percentage change in labour productivity between the two methods.

6. Calculate the QALI percentage pay share for workers in the base case.

7. Calculate the QALI percentage pay share for workers in the new approach

8. From steps 8 and 9 , calculate the average pay shares between the two, the percentage change in hours worked and the percentage change in QALI

a) Percentage change in hours is the difference in hours worked for each job category (see step 3 for both scenarios)

b) Percentage change in QALI is average pay shares multiplied by the percentage change in hours worked, which is subsequently totalled. 
9. The difference between change in output (see step 6) and total change in hours worked (see step 10) is the non-QALI change in labour output per hour by switching from the base case to the new approach.

10. As in step 11, we repeat for a QALI view that takes account of the effects of Human Capital. The difference between change in output (see step 6) and total change in QALI (see step 10) is the QALI change in labour output per hour.

11. The difference between steps 11 and 12 is the change in labour composition by moving from the base case to a new approach.

\section{Calculating Capital Inputs}

1. Next we look at capital services. This could include preliminaries such as site cabins, plant hire, and sub-contractors. We calculate the costs over the life of the project and convert that to an average daily cost. Finally, we calculate the cost shares of each type of capital service. This is done for both the base case and the new approach.

2. In a similar fashion to what we did with QALI, we now find the average cost shares, the percentage change in costs per day and finally the percentage change in capital services.

a) Percentage change in capital services is average cost shares multiplied by the percentage change in costs per day which is subsequently totalled.

\section{Calculating Gross Value Added}

1. We now look to the value added. From financiers we need to know the Weighted Average Cost of Capital. This is the cost of borrowing money to fund the project and we need a return that is higher than this if the scheme is to be profitable. This percentage is used as a discount factor in net present value calculations.

2. Next we need to calculate the net present value of future revenues enabled by the projects. First for the base case and then for the new approach. This is where creativity and the consideration of functionality can make a difference to total project value. Once we have the net present value we divide that by the number of calendar project days so we have an equivalent view of daily revenue. This is where we also articulate functional and non-functional requirements that are used to inform design teams.

3. The cost of sales per day is taken as the output per day (see step 2). This is done for both the base case and the new approach.

4. The Gross Value Added per day is found by subtracting the cost of sales per day (see step 18) from the daily net present value of revenues (see step 18).

5. Residual Profit is found by subtracting labour costs per day (see step 3) and total average capital costs per day (see step 14) from Gross Value Added per day (see step 19). This is calculated for both the base case and the new approach.

6. Calculate the percentage growth in the equivalent daily revenues for both scenario (see step 17).

7. Calculate the percentage growth in Gross Value Added (GVA) per day (see step 19) 


\section{Calculating alpha and beta}

Crafts (2008) says the capital share $(\alpha)$ is typically between 0.25 and 0.4 . That is a view from the macroeconomic level and research at the project level remains to be undertaken.

1. To calculate beta $(\beta)$ we find the total labour costs (see step 3 ) as a percentage of GVA (see step 19) for both scenario then average the two.

2. Because our assumption is a constant return to scale, we find alpha by subtracting beta from 1
a. $\alpha=1-\beta$
Calculating MFP

1. We can now calculate MFP for the move from the base case to the new approach.

a) Percentage change in total output (GVA) (see step 6)

b) Percentage weighted change in QALI = Total percentage change in QALI (see step 10) multiplied by $\beta$ (see step 23)

c) Percentage weighted change in capital services $=$ Total percentage change in capital services (see step 15) multiplied by $\alpha$ (see step 24)

d) $M F P=$ Percentage change in total output (GVA) minus Percentage weighted change in QALI minus Percentage weighted change in capital services

2. We can calculate MFP on an hourly basis and we should get the same answer as in step 25.

a) Change in labour output per hour (see step 11)

b) Weighted change in labour composition = change in labour composition (see step 13) multiplied by $\beta$ (see step 23)

c) Weighted change in capital services per hour $=$ [change in hours (see step 10) minus change in capital services per hour (see step 15)] multiplied by $\alpha$ (see step 24)

d) MFP = Change in labour output per hour minus Weighted change in labour composition minus Weighted change in capital services per hour.

\section{Assumptions}

To aid clarity of explanation and limit the size of this paper we have made a number of assumptions. We have ignored taxation effects. We also ignored whether the money a subcontractor is paid by the Government is spent in-country or abroad. Remember, an assumption of MFP is that it has spill over effects that raise living standards. If payments go $100 \%$ offshore then those spill over benefits may be lost to the funding Government and be realised in a different economy abroad.

\section{Conclusions}

This paper offers a way to solve the Productivity Puzzle by considering capital projects in the conceptual stages and learning how MFP calculations vary during project execution. This could be valuable to Governments as it would help them assess which investments are likely to have more spill over benefits that lift the living standards of its citizens. This approach is in contrast to methods typically used by economists where historic data is investigated with mathematical techniques such as multiple regression.

A positive MFP suggests the new approach is better than the base case in terms of its benefit to economic growth. Understanding approximate contributions a major capital project could have on economic growth enables a Government to make more informed choices about the way their capital projects unlock technological progress and spill over benefits that raise living standards beyond the project itself. 
Most capital investment methods (e.g. NPV, IRR, PI etc.) need to demonstrate positive results before investors give an approval to proceed and funds are sanctioned. This is well established. Yet evidence from around the world shows negative productivity exists which means what counts as success from investment appraisal techniques may not actually be successful for the economy and GDP growth.

We accept a need to maintain proven investment appraisal techniques to satisfy the needs of financiers. What we call for is to also make the MFP calculation part of a Government's investment appraisal criteria.

In this paper we made a number of assumptions and omissions (e.g. taxation was omitted) to keep our explanation simple and to show how MFP enables valuable a priori insights. Those insights could be used in capital projects to unlock new levels of prosperity for a nation's citizens as well as meeting the requirements of the usual stakeholders in capital projects.

\section{References}

Abramovitz, M., 1956. Resource and Output Trends in the United States Since 1870. The American Economic Review, Volume 46(2), pp. 1-23

Arrazola, M., de Hevia, J., 2004. More on the Estimation of the Human Capital Depreciation Rate. Applied Economics Letters, Volume 11(3), pp. 145-148

Arrow, K., 1962. The Economic Implications of Learning by Doing. The Review of Economic Studies. Oxford University Press. Volume 29(3), pp. 155-173

Barro. R.J., 1999. Notes on Growth Accounting. Journal of Economic Growth, Volume 4, pp. 119-137

Baumol, W., 1986. Productivity Growth, Convergence and Welfare. American Economic Review, Volume 76, pp. 1072-1085

Berawi, M.A., Susantono, B., Miraj, P., Berawi, A.R.B., Rahman, H.Z., Gunawan, Husin, A., 2014. Creating Value-Added and Increasing Feasibility of Mega Infrastructure Projects. Procedia Technology, Volume 16, pp. 1037-1046

Berawi, M.A., 2006. Distinguishing Concept Types in Function Models during the Act of Innovation. Master's Dissertation, Graduate Program, Oxford Brookes University, United Kingdom

Berawi, M.A., 2018. The Fourth Industrial Revolution: Managing Technology Development for Competitiveness. International Journal of Technology, Volume 9(1), pp. 1-4

Berawi, M.A., Woodhead, R.M., 2005. How-Why Logic Paths and Intentionality. Value World, Volume 28(2), pp. 12-15

Berawi, M.A., Woodhead, R.M., 2008. Stimulating Innovation using Function Models: Adding Product Value. Value World, Volume 31(2), pp. 4-7

Canarella, G., Pollard, S.K., 2003. The Augmented Solow Model and the OECD Sample. International Business \& Economics Journal, Volume 2(7), pp. 89-102

Christensen, C., 2016. The Innovator's Dilemma: When New Technologies Cause Great Firms to Fail (Management of Innovation and Change). Reprint edition. Cambridge, Mass: Harvard Business Review Press

Cobb, C.W., Douglas, P.H., 1928. A Theory of Production. American Economic Review, Volume 18, pp. 139-165

Crafts, N., 2008. What Creates Multi-factor Productivity. Paper prepared for the joint ECB, Banque de France and The Conference Board conference "The Creation of Economic and Corporate Wealth in a Dynamic Economy", Frankfurt, January. Available online https://warwick.ac.uk/fac/soc/economics/staff/nfrcrafts/working_papers/mfp.pdf, Accessed on July 26, 2019 
DeLong, J.B., 1988. Productivity Growth, Convergence and Welfare: Comment. American Economic Review, Volume 78, pp. 1138-1154

Franklin, M., 2018. A Simple Guide to Multi-Factor Productivity. Available Online at https://www.ons.gov.uk/economy/economicoutputandproductivity/productivityme asures/methodologies/asimpleguidetomultifactorproductivity, Accessed on 26th July 2019

Goodridge, P., Haskel, J., Wallis, G., 2018. Accounting for the UK Productivity Puzzle: A Decomposition and Predictions. Economica, Volume 85, pp. 581-605

Groot, W., 1998. Empirical Estimates of the Rate of Depreciation of Education. Applied Economics Letters, Volume 5(8), pp. 535-538

Harris, R., Moffat, J., 2017. The UK Productivity Puzzle, 2008-2012: Evidence using PlantLevel Estimates of Total Factor Productivity. Oxford Economic Papers, Volume 69(3), pp. 529-549

Haskel, J., Westlake, S., 2018. Capitalism without Capital. Oxford: Princetown University

Kaufman, J.J., Woodhead, R.M., 2006. Stimulating Innovation in Products and Services. Hoboken NJ: Wiley

Kroes, P.A., 1998. Technological Explanations: the Relation between Structure and Function of Technological Objects, Virginia Tech, Volume 3(3), pp. 124-134

Leonard-Barton, D., 1995. Wellsprings of Knowledge; Building and Sustaining the Sources of Innovation. Boston, Mass: Harvard Business School Press

Male, S., Gronqvist M., Kelly, J., Graham, D., 2007. Managing Value as a Management Style for Projects. International Journal of Project Management, Volume 25(2), pp. 107-114

Marx, K., Engels, F., 1976. Marx-Engels Collected Works: Volume 6: Marx and Engels, 18451848. New York: International Publishers

Nonneman, W., Vanhoudt, P., 1995. A Further Augmentation of the Solow Model and the Empirics of Economic Growth for OECD Countries. The Quarterly Journal of Economics, Volume 111(3), pp. 943-953

Romer, P.M., 1990a. Endogenous Technological Progress. Journal of Political Economy, Volume 98(5), pp. 71-102

Romer, P.M., 1990b. Capital, Labor, and Productivity. Brookinigs Papers: Microecononmics

Rosenberg, N., 2004. Innovation and Economic Growth. Paris, France: Organisation for Economic Cooperation and Development (OECD)

Schumpeter, J., 1942. Capitalism, Socialism and Democracy. $3^{\text {rd }}$ Edition. New York: Harper \& Row

Seni, D.A., 2005. Function Models: A General Framework for Technological Design. Value World, Volume 28(2), pp. 8-11

Smith, A., 1776. An Inquiry into the Nature and Causes of the Wealth of Nations. Chicago, USA: The University of Chicago Press. ISBN: 0-226-76374-9

Solow, R., 1956. A Contribution to the Theory of Economic Growth. The Quarterly Journal of Economics, Volume 70(1), pp. 65-94

Solow, R.M., 1957. Technological Progress and the Aggregate Production Function. Review of Economics and Statistics, Volume 39, pp. 312-320

Swan, T.W., 1956. Economic Growth and Capital Accumulation. Economic Record, Volume 32, pp. 334-361

Teece D.J., 2015. Intangible Assets and a Theory of Heterogeneous Firms. Forthcoming chapter for Bounfour A., Miyagawa T. (eds), Intangibles, Market Failure and Innovation Performance. New York: Springer

Teschl, E., 2018. An Analysis of Expectations in Industrial Value Engineering Projects. European Journal of Business Science and Technology, Volume 4(2), pp. 196-215 
Visser, W., 2019. Integrated Value Management: Implementing Sustainable Transformation. AMS Sustainable Transformation Briefing Series, Belgium: Antwerp Management School

Wiratmadja, I.I., Govindaraju, R., Handayani, D., 2016. Innovation and Productivity in Indonesian IT Clusters: The Influence of External Economies and Joint Action. International Journal of Technology, Volume 7(6), pp. 1097-1106

Woodhead, R.M., 2001. An Investigation of the Early Stages of Project Formulation. Facilities, Volume 18(13-14), pp. 524-534

Woodhead, R.M., 2012. What is Technology? International Journal of Sociotechnology and Knowledge Development, Volume 4(2), pp 1-13

Woodhead, R.M., Male, S.P., 2000. The Conditioning Effect of Objective Decision Making on the Client's Capital Proposal. Engineering Construction and Architectural Management, Volume 7(3), pp. 300-306 